\title{
Hair zinc level in Down syndrome
}

\section{Ayse Yenigun', Ferda Ozkinay², Ozgur Cogulu' ${ }^{2}$, Canan Coker ${ }^{3}$, Nurten Cetiner $^{4}$, Gonca Ozden ${ }^{4}$, Oguz Aksu ${ }^{2}$ and Cihangir Ozkinay ${ }^{2}$}

\author{
'Adnan Menderes University, Faculty of Medicine, Department of Pediatrics, Aydin, Turkey \\ ${ }^{2}$ Ege University, Faculty of Medicine, Department of Pediatrics, Izmir, Turkey \\ ${ }^{3}$ Dokuz Eylul University, Faculty of Medicine, Department of Biochemistry, Izmir, Turkey \\ ${ }^{4}$ Ege University Faculty of Medicine, Research Laboratory, Izmir, Turkey
}

\begin{abstract}
Immunological, endocrinological, and haematological abnormalities are relatively common in people with Down syndrome (Cuadrado \& Barrena, 1996; Decoq \& Vincker, 1995; Hestnes et al., 1991; Sustrova \& Strbak, 1994; Nespoli, Burgio, Ugazio \& Maccario, 1993; Kempski, Chessells \& Reeves, 1997; Kivivuori, Rajantie, \& Siimes, 1996; David et al., 1996; Gjertson, Sturm \& Berger, 1999). Zinc is one of the elements that act in the maintenance of normal function of these systems. This study was designed to investigate zinc levels in children with Down syndrome. Zinc levels were measured in hair using atomic absorption spectrophotometry. The hair zinc level of 19 children with Down syndrome was compared with the zinc level of II typically developing children. Hair zinc levels were found to be significantly lower $(p<.05)$ in those with Down syndrome (average $95.18 \pm 56.10 \mathrm{ppm}$ ) than in the typically developing children (average $208.88 \pm 152.37$ $\mathrm{ppm}$ ). Some of the problems experienced by children with Down syndrome may be due to these low zinc levels, but further research is required to confirm these results, and to establish any correlation with these problems.
\end{abstract}

Keywords: Down syndrome, hair analysis, zinc

\section{Introduction}

Zinc is an important element in protein synthesis and gene expression involving the immune and endocrinological systems. Zinc deficiency may play a crucial role in some of the pathological manifestations associated with Down syndrome such as infections and malfunctioning of the thyroid gland (Bjorksten et al, 1980; Sustrova, \& Strbak, 1994).

There have been a number of studies showing that low zinc levels occur in many children with Down syndrome and that oral zinc supplementation may be useful in correcting some of the immune and endocrinological disorders associated with thyroid dysregulation in these children (Franceschi et al., 1988; Kadrabova, Madaric, Sustrova \& Ginter, 1996; Licastro et al., 1994; Licastro et al., 1992).

It has been reported that oral zinc supplementation is effective in normalising plasma zinc levels, thymulin and TSH levels in children with Down syndrome with zinc deficiency (Licastro et al., 1994; Licastro et al., 1992). Clinical evaluation of children with Down syndrome has also shown that zinc supplementation decreased the incidence of infectious diseases, and improved school performance (Franceschi et al., 1988; Licastro et al., 1992).
Hair was used as a biopsy material reflecting the elemental status of the body (Schlegel-Zawadzka, Zachwieja, HuziorBaajewicz \& Pietrzyk, 2002; Misra, Srivastava \& Chawla, 1989; Chen, Lin, Lin \& Cheng, 1988; Cavdar, Bahceci, Akar, Dincer \& Erten, 1991). Trace elements in hair, in particular zinc, are being widely investigated (Deeming \& Weber, 1977; Deeming \& Weber, 1978; Delves, 1985; Kozielec, Starobrat \& Kotkowiak, 1994; Litzman, Dastych \& Hegar, 1995). Low hair zinc level has been shown to be a good indicator of mild to moderate zinc deficiency (Prasad, 1983; Davies, 1984; Passwater \& Cranton, 1983; Hambridge, 1982). Nevertheless hair zinc level is elevated due to impaired hair growth in severe zinc deficiencies (Davies, 1984; Passwater \& Cranton, 1983).

In this study we aimed to evaluate the zinc level in children with Down syndrome using hair, which is easily and noninvasively obtained. We also compared the hair zinc levels of children with Down syndrome with typically developing children. 


\section{Methods and Materials}

Hair samples were collected from the suboccipital area (the base of the back of skull), by cutting with stainless steel scissors, of 19 children with Down syndrome (age range: 2-6 years old) and 11 age matched typically developing children. The proximal ends of the samples of hair were usually within $2 \mathrm{~cm}$ of the scalp, approximately $0.3 \mathrm{~g}$, were used for the analysis. In each of these samples the procedures described below were applied.

Acetone-water wash: Hair samples were placed in $100 \mathrm{ml}$ beakers, covered with bidistilled-deionized water and agitated for 10 minutes with a mechanical shaker. The water was then decanted and replaced with acetone (Merck 13).

The samples were washed four times with acetone each being agitated for a period of 10 minutes and subsequently rinsed with water. After being washed the hair samples were dried at $60^{\circ} \mathrm{C}$ for 16 hours followed by cooling to room temperature and finally reweighed on an analytical balance.

Wet digestion: hair samples were placed in $100 \mathrm{ml}$ wide mouthed pyrex beakers and left to digest in $5 \mathrm{ml}$ reagent grade nitric acid (Merck 925) overnight. The following morning $10 \mathrm{ml}$ of perchloric acid (Merck 519): nitric acid ( $1 / 4$ by volume) was added. All samples were covered with watch glasses and refluxed at $200^{\circ} \mathrm{C}$ for about 8 hours until a clear residue of 2-3 $\mathrm{ml}$ remained. After cooling for one hour the digested samples were decanted into $25 \mathrm{ml}$ volumetric flasks and brought to volume with added rinsings of bidistiled-deiodinized water.

Zinc measurements were done by atomic absorption spectrometry (AAS), using a Pye Unicam SP9. The zinc hollow cathode lamp current was $5 \mathrm{~mA}$ and the wave length was $213.9 \mathrm{~nm}$, slit width $0.5 \mathrm{~nm}$. Results were expressed in parts per million (ppm).

Mean \pm standard error of mean values of $\mathrm{Zn}$ of both groups in hair were calculated for each group. Anova analysis was used to compare both groups. The $95 \%$ confidence interval (CI) on the mean was calculated. Chisquare test was used to compare the cases out of $95 \% \mathrm{CI}$.

The statistical analyses of the results were calculated in SPSS for Windows.

\section{Results}

The results of zinc concentrations of both groups and the comparison of hair zinc levels are presented in Table 1. The mean zinc level was $95.18 \pm 56.10$ ppm (range: 19.60 $191.50)$ in Down syndrome children, and $208.88 \pm 152.37$ ppm (range: 52.41-558.53) in typically developing children. Zinc concentrations in hair samples of children with Down syndrome were significantly lower than the typically developing children $\left(\mathrm{F}_{(1,28)}=8.732, \mathrm{p}<.05\right)$. The $95 \%$ confidence interval of the group of typically developing cases was

(a)

(b)

\begin{tabular}{|c|c|c|c|}
\hline \multicolumn{2}{|c|}{ Children with Down syndrome } & \multicolumn{2}{|c|}{ Typically developing children } \\
\hline Case & Zinc (ppm) & Case & Zinc (ppm) \\
\hline 1 & 27.22 & $\mathrm{I}$ & 329.71 \\
\hline 2 & 130.11 & 2 & 256.67 \\
\hline 3 & 34.00 & 3 & 558.53 \\
\hline 4 & 62.32 & 4 & 107.25 \\
\hline 5 & 135.29 & 5 & 154.30 \\
\hline 6 & 153.53 & 6 & 78.24 \\
\hline 7 & 52.00 & 7 & 201.74 \\
\hline 8 & 46.44 & 8 & 76.96 \\
\hline 9 & 137.70 & 9 & 52.41 \\
\hline 10 & 60.20 & 10 & 144.33 \\
\hline II & 161.00 & 11 & 337.53 \\
\hline 12 & 90.40 & & \\
\hline 13 & 52.70 & & \\
\hline 14 & 147.86 & & \\
\hline 15 & 162.14 & & \\
\hline 16 & 19.60 & & \\
\hline 17 & 118.20 & & \\
\hline 18 & 26.19 & & \\
\hline 19 & 191.50 & & \\
\hline
\end{tabular}

\begin{tabular}{lccc}
\hline & \multicolumn{3}{c}{ Hair zinc levels (ppm) } \\
& mean \pm SD & SEM & Range \\
\cline { 2 - 4 } $\begin{array}{l}\text { Children with Down syndrome } \\
(n=19)\end{array}$ & $95.18 \pm 56.10$ & 12.87 & $19.60-191.50$ \\
$\begin{array}{l}\text { Typically developing children } \\
(n=11)\end{array}$ & $208.88 \pm 152.37$ & 45.94 & $52.41-558.53$ \\
\hline
\end{tabular}

Table I. (a) The levels of hair zinc in Down syndrome and typically developing children (b) The mean, SEM and range of zinc levels in Down syndrome and typically developing children

$102.36 \mathrm{ppm}$. The number of Down syndrome and typically developing cases out of the lower limit of $95 \%$ CI (106.52 $\mathrm{ppm}$ ) is shown in Table 2. There was no significant difference between the number of Down syndrome and typically developing cases below 95\% CI $\left(\mathrm{X}^{2}=1.824, \mathrm{df}=1, \mathrm{~ns}\right)$.

\section{Discussion}

In the present study we used hair to evaluate the zinc levels in children with Down syndrome. We found hair zinc levels of children with Down syndrome were significantly lower than those of the typically developing children. Zinc is an important trace element in metabolism, growth and development and reproduction. It is a constituent of many enzymes. Zinc also plays important roles in nucleic acid metabolism and protein synthesis as well as membrane structure and function. Its deficiency causes impaired growth, poor appetite and physiological changes. Zinc 


\begin{tabular}{lcc}
\hline & Down syndrome & Typically developing \\
\hline Lower * & 10 & 3 \\
Within & 9 & 8 \\
\hline
\end{tabular}

* The number of children below $95 \% \mathrm{Cl}$

Table 2. The number of cases below / within $95 \%$ confidence interval for zinc levels

deficiency is also associated with low levels of antibodies. Sustrova and Strbak (1994) reported a high occurrence rate of complex immune and endocrine disorders with thyroid dysregulation in people with Down syndrome, with zinc deficiency playing a considerable role. There is a susceptibility to respiratory infection in children with Down syndrome, and this is one of the major factors in their early mortality. A number of investigations including zinc status have been performed to prevent these infections (Teksen, Sayli, Aydin, Sayal \& Işimer, 1998). It has been found that zinc deficiency plays an important role in immunglobulin concentrations and thyroid function (Franceschi et al., 1988; Licastro et al., 1994; Licastro et al., 1992; Sustrova \& Strbak, 1994). However no significant difference was also found between children with Down syndrome with normal zinc levels and low zinc levels regarding the measures of growth hormone secretion, Ig A and Ig $\mathrm{G}$ antigliadin antibodies, presence of celiac disease, thyroid function tests, CD4/CD8 ratio and total immunoglobulins in another study (Romano et al., 2002). Hair zinc level has also been evaluated in a range of different clinical situations. Mean hair and serum zinc levels were found to be much lower in Indian childhood cirrhosis than the age-matched healthy controls (Misra, Srivastava \& Chawla, 1989). Chen et al. (1988) found the serum and hair zinc controls in obese patients markedly lower than in non-obese patients. Litzman et al. (1995) found a significant decrease in serum zinc levels in common variable immunodeficiency patients. It was found that zinc therapy not only improves the immune system, but also accelerates growth (Napolitano, et al., 1990). Kozielec et al. (1994) showed that it was necessary to supplement trace elements in children with hyperactivity.

Zinc status can be evaluated by using serum, urine, saliva and hair. Although body fluids and tissues are commonly used methods, no correlation has been found between those specimens (Delves, 1985). Hair may be used as a biopsy material reflecting the level of zinc status of the body. Deeming and Weber (1977) evaluated hair analysis for determination of zinc status using rats and reported that hair zinc analysis could be used to aid diagnosis of a deficiency or evaluate dietary intake. Furthermore once incorporated into hair, zinc is no longer in equilibrium with the body and therefore not susceptible to circadian variation (Coker, Cetiner, Sozmen \& Ersoz, 1996; Yenigun, Oksel, Bozdogan \& Taneli, 1996; Yenigun, Taneli \& Kultursay, 1991). The advantages of hair as a source are that it is easy to obtain and stable in storage. It is not affected from the daily variations of food intake. On the other hand, there is a lack of concordance in the results of different laboratories in the assessment and analysis of zinc deficiency (Capel, Spencer, Daivies \& Levitt, 1985; Deeming \& Weber, 1978; Delves, 1985; Lockitch et al., 1989). It has been reported that hair zinc level reflects the body zinc level (Bilir, Kayakirilmaz, Guven, Atik \& Ugurlu, 1987; Chen et al., 1985; Klevay, 1970). Deeming \& Weber (1978) reported that mineral concentration of hair, serum and diet do not correlate well. Age, sex and body mass index have been reported to be some of the influencing factors that affect the concentration of zinc in the hair (Chen et al., 1985; de Mateo, Perez \& Mijan de la Torre, 2000). Klevay (1970) suggested the use of hair as a biopsy material in the evaluation of zinc status by comparing the levels to an age-matched typically developing control group. Our control group was age-matched with the study group, which ranged between 2-6 years old. However, food habits and frequency of intake of different products also influence zinc concentration in hair (Schlegel-Zawadzka et al., 2002; Deeming \& Weber, 1978).

These findings indicate that zinc level is influenced by a number of external and internal factors and correction of the zinc level is necessary for the control of biological processes in children with Down syndrome who are vulnerable to zinc deficiency. Therefore zinc level for an individual with Down syndrome may be judged to be deficient after comparing with the age-matched control group from the similar environment. Hair zinc level was investigated in a few studies and ranged between 118 and 152 microgram/g. The mean level of typically developing children was found to be $208.88 \pm 152.37 \mathrm{ppm}$ in the present study. Coker et al. (1996) analyzed hair zinc levels in 24 typically developing children and found a similar mean value to the present study (238.5 microgram/g). The mean hair zinc level in our study was $95.18 \pm 56.10 \mathrm{ppm}$ in children with Down syndrome. Accepting the hair zinc values outside of a $95 \%$ confidence interval from typically developing children to be abnormal, there is no significant difference between the two groups in the current study. De Mateo et al. (2000) analyzed the zinc status in a healthy, adult, Spanish population. A predictive model of multiple regression was obtained for zinc in hair which is associated with age, sex and BMI. Similar investigations with larger study groups for different populations may be helpful to standardize the hair zinc level, which is an easily obtained and non-invasive biopsy material.

In conclusion, we aimed to investigate the levels of hair zinc in children with Down syndrome by comparison with typically developing controls, therefore we cannot comment on the usefulness of zinc supplementation for children with Down syndrome. Nevertheless zinc supplementation may be useful at least in individuals with Down syndrome with lower hair zinc levels, which is recommended by many authors to reduce the incidence of problems such as infections and endocrinological but further clinical research is required to support this suggestion. 


\section{Correspondence}

Ozgur Cogulu, MD • Ege University Faculty of Medicine, Department of Pediatrics, 35100 Bornova, Izmir, Turkey • Tel. +90-232-339 81 98 • Fax. +90 2323398781 • e-mail: cogulu@med.ege.edu.tr

\section{References}

Bilir, S., Kayakirilmaz, K., Guven, N., Atik B. \& Ugurlu M. (1987). Down sendromlu çocuklarda serumda ve saçta çinko, bakır ve demir düzeylerinin tayini ve fiziksel gelişim durumlarının normal çocuklarla karşılaştırılması. (Turkish) (Determination of zinc, copper, and iron levels of hair and serum in Down syndrome children and comparison of development with the normal children). Cocuk gelişimi ve eğitim dergisi (Journal of Child Development and Education), 2, 9-23.

Bjorksten, B., Back, O., Gustavson, K.H., Hallmans, G., Hagglof, B. \& Tarnvik, A. (1980). Zinc and immune function in Down's syndrome. Acta Paediatrica Scandinavica, 69, 183-7.

Capel, I.D., Spencer, E.P., Daivies, A.E. \& Levitt, H.N. (1985). The assessment of zinc status by the zinc tolerance test in various groups of patients. Journal of Clinical Endocrinology and Metabolism, 14, 725-60.

Cavdar, A.O., Bahceci, M., Akar, N., Dincer, F.N. \& Erten, J. (1991). Maternal hair zinc concentration in neural tube defects in Turkey. Biological Trace Element Research, 30, 81-5.

Chen, M.D., Lin, P.Y., Lin, W.H. \& Cheng, V. (1988). Zinc in hair and serum of obese individuals in Taiwan. American Journal of Clinical Nutrition, 48, 1307-9.

Chen, X.C., Yin, T.A., He, J.S., Ma, Q.Y., Han, Z.M. \& Li, L.X. (1985). Low levels of zinc in hair and blood, pica, anorexia and poor growth in Chinese preschool children. American Journal of Clinical Nutrition, 42, 694-700.

Coker, C., Cetiner, N., Sozmen, E. \& Ersoz, B. (1996). Analysis of hair copper and zinc. Medical Journal of Ege University, 6, 1-3.

Cuadrado, E. \& Barrena, M.J. (1996). Immune dysfunction in Down's syndrome: primary immune deficiency or early senescence of the immune system? Clinical Immunology and Immunopathology, 78, 209-14.

David, O., Fiorucci, G.C., Tosi, M.T., Altare, F., Valori, A., Saracco, P., Asinardi, P., Ramenghi, U. \& Gabutti, V. (1996). Hematological studies in children with Down syndrome. Pediatric Hematology and Oncology, 13, 2715 .

Davies, S. (1984). Assessment of zinc status. International Clinical Nutrition Review, 4, 122-9.

de Matteo, S.B., Perez, G.A. \& Mijan de la Torre, A. (2000). The zinc status in a selected Spanish population. A multivariate analysis. Nutrición Hospitalaria, 15, 32-41.

Decoq, P. \& Vinckier, F.(1995). Down syndrome: 1. Medical aspects. Revue Belge de Medecine Dentaire, 50, 43-52.

Deeming, S.B. \& Weber, C.W. (1977). Evaluation of hair analysis for determination of zinc status using rats. American Journal of Clinical Nutrition, 30, 2047-52.

Deeming, S.B. \& Weber, C.W. (1978). Hair analysis of trace minerals in human subjects as influenced by age, sex, and contraceptive drugs. American Journal of Clinical Nutrition, 31, 1175-80.

Delves, H.T. (1985). Assessment of trace element status. Journal of Clinical Endocrinology and Metabolism, 14, 725-60.

Franceschi, C., Chiricolo, M., Licastro, F., Zannotti, M., Masi, M., Mocchegiani, E. \& Fabris, N. (1988). Oral zinc supplementation in Down's syndrome: restoration of thymic endocrine activity and of some immune defects. Journal of Mental Deficiency Research, 32, 169-81.

Gjertson, C., Sturm, K.S. \& Berger, C.N. (1999). Hematopoietic deficiencies and core binding factor expression in murine Ts16, an animal model for Down syndrome. Clinical Immunology, 91, 50-60.

Hambridge, K. (1982). Hair analysis: Worthless for vitamins, limited for minerals. American Journal of Clinical Nutrition, 36, 943-9.

Hestnes, A., Stovner, L.J., Husoy, O., Folling, I., Fougner, K. J. \& Sjaastad, O. (1991). Hormonal and biochemical disturbances in Down's syndrome. Journal of Mental Deficiency Research, 35, 179-93.

Kadrabova, J., Madaric, A., Sustrova, M. \& Ginter E. (1996). Changed serum trace element profile in Down's syndrome. Biological Trace Element Research, 54, 201-6.

Kempski, H.M., Chesells, J.M. \& Reeves, B.R. (1997). Deletions of chromosome 21 restricted to the leukemic cells of children with Down syndrome and leukemia. Leukemia, 11, 1973-7.

Kivivuori, S.M., Rajantie, J. \& Siimes, M.A. (1996). Peripheral blood cell counts in infants with Down's syndrome. Clinical Genetics, 49, 15-9.

Klevay, L.M. (1970). Hair as a biopsy material. I, Assestment of zinc nutriture. American Journal of Clinical Nutrition, 23, 284-9.

Kozielec, T., Starobrat, H.B. \& Kotkowiak, L. (1994). Deficiency of certain trace elements in children with hyperactivity. Psychiatria Polska, 28, 345-53.

Licastro, F., Chiricolo, M., Mocchegiani, E., Fabris, N., Zannoti, M., Beltrandi , E., Mancini, R., Parente, R., Arena, G. \& Masi, M. (1994). Oral zinc supplementation in Down's syndrome subjects decreased infections and normalized some humoral and cellular immune parameters. Journal of Intellectual Disability Research, 38, 149-62.

Licastro, F., Mocchegiani, E., Zannotti, M., Arena, G., Masi, M. \& Fabris, N. (1992). Zinc affects the metabolism of thyroid hormones in children with Down's syndrome: normalization of thyroid stimulating hormone and of reversal triiodothyronine plasmic levels by dietary zinc supplementation. International Journal of Neuroscience, $65,259-68$

Litzman, J., Dastych, M. \& Hegar, P. (1995). Analysis of zinc, iron and copper serum levels in patients with common variable immunodeficiency. Allergologia et Immunopathologia (Madrid), 23, 117-20.

Lockitch, G., Puterman, M., Godolphin, W., Sheps, S., Tingle, A.J. \& Quigley, G. (1989). Infection and immunity in Down syndrome: a trial of long-term low oral doses of zinc. Journal of Pediatrics, 114, 781-7.

Misra, P.K., Srivastava, K.L. \& Chawla, A.C. (1989). Serum and hair zinc in Indian childhood cirrhosis. Indian Pediatrics, 26, 22-5. 
Napolitano, G., Palka, G., Grimaldi, S., Giuliani, C., Laglia, G., Calabrese, G., Satta, M.A., Neri, G. \& Monaco, F. (1990). Growth delay in Down syndrome and zinc sulphate supplementation. American Journal of Medical Genetics Supplement, 7, 63-5.

Nespoli, L., Burgio, G.R., Ugazio, A.G. \& Maccario, R. (1993). Immunological features of Down's syndrome: a review. Journal of Intellectual Disability Research, 37, 543-51.

Passwater, R. \& Cranton E. (1983). Trace elements, hair analysis and nutrition. New Canaan, Connecticut: Keats Publishing Inc.

Prasad, A. (1983). Clinical, biochemical and nutritional spectrum of zinc deficiency in human subjects. An update. Nutrition Reviews, 41, 197-208.

Romano, C., Pettinato, R., Ragusa, L., Barone, C., Alberti, A. \& Failla, P. (2002). Is there a relationship between zinc and the peculiar comorbidities of Down syndrome? Down Syndrome Research and Practice, 8(1), 25-8.

Schlegel-Zawadzka, M., Zachwieja, Z., Huzior-Baajewicz, A. \& Pietrzyk, J.J. (2002). Comparative analysis of zinc status, food products' frequency intake and food habits of 11-year-old healthy children. Food Additives and Contaminants, 19, 963-8.
Sustrova, M. \& Strbak, V. (1994). Thyroid function and plasma immunoglobulins in subjects with Down's syndrome (DS) during ontogenesis and zinc therapy. Journal of Endocrinological Investigation, 17, 385-90.

Teksen, F., Sayli, B.S., Aydin, A., Sayal, A. \& Işimer, A. (1998). Antioxidative metabolism in Down Syndrome. Biological Trace Element Research, 63, 123-127.

Yenigun, A., Oksel, F., Bozdogan, N. \& Taneli, B. (1996). Zinc in serum and breast milk in women who felt that their milk supply is depressed. Medical Journal of Ege University, 6, 47-51.

Yenigun, A., Taneli, B. \& Kultursay, N. (1991). Anne sütü ve serum eser elementleri arasındaki ilişki (Turkish) (Relations between breast milk and serum trace elements). Ege Tip Dergisi (Medical Journal of Ege University), 30, 389-391.

\section{the DOWN SYNDROME educational trust}

\section{Practical advice for parents and teachers based} on the latest research

Workshops throughout the year for parents, teachers, special educational needs coordinators, speech and language therapists.

Conferences for parents: Parent and Family Weekends take place at The Sarah Duffen Centre twice a year.

Specialist products, including books, videos, teaching materials and computer software, all carefully selected by the Trust.

DownsEd publications including:

- Down Syndrome Issues and Information, a new series of books for parents and professionals, providing comprehensive information and practical advice on the development and education of children with Down syndrome.

- Down Syndrome News and Update, a journal for parents and professionals, recently relaunched in a new magazine format.

- Down Syndrome Research and Practice, a peer-reviewed journal for professionals and academics.

By producing our publications in-house, we are able to provide employment for adults with Down syndrome.

For further information please call, e-mail or visit our web site:

The Down Syndrome Educational Trust

tel: $+44(0) 2392855330$

e-mail: enquiries@downsed.org

web site: http://www.downsed.org/

The Down Syndrome Educational Trust is a charity registered in England and Wales. Charity number 1062823.

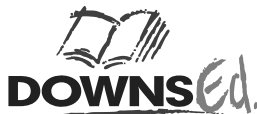

